TITLE:

\title{
Impaired facial emotion recognition and reduced amygdalar volume in schizophrenia(Abstract_要旨)
}

AUTHOR(S):

Namiki, Chihiro

CITATION:

Namiki, Chihiro. Impaired facial emotion recognition and reduced amygdalar volume in schizophrenia. 京都大学, 2008, 博士(医学)

\section{ISSUE DATE:}

2008-09-24

URL:

http://hdl.handle.net/2433/124236

RIGHT: 
